\section{Damning verdict on cold fusion}

SIR - Del Giudice and Preparata ${ }^{1}$ complain about the report and comments in Nature, ${ }^{2,3}$ that an Italian court had rejected the libel action that Drs M. Fleischmann, S. Pons, T. Bressani, E. Del Giudice and G. Preparata had brought against the editor, publisher and scientific editor (Giovanni Maria Pace) of La Repubblica newspaper, claiming 8 billion lire. Pace had written of cold fusion as being similar to scientific fraud.

La Repubblica asked me to provide the scientific and historical evidence ${ }^{4}$, so I should like to mention some facts missing from Del Giudice and Preparata's letter, such as that the court not merely rejected the claim of the five but also awarded costs against them.

Del Giudice and Preparata write that the comments in Nature 2,3 "might convince readers that an Italian court has actually found a proof of misconduct by Martin Fleischmann, Stanley Pons and the three Italian scientists", but in fact Nature did not make such accusations - it simply said that the five had lost a libel case and quoted parts of the judgement.

The court judgement was very skilfully written: it does not give a clear scientific judgement on cold fusion but rather says the evidence is such that it is not unreasonable for a journalist to express opinions similar to those of Pace. When the US government wished to make a scientific judgement on cold fusion, it appointed a panel of 22 distinguished scientists who severely criticized the work of Fleischmann and Pons and concluded that there was no compelling evidence for cold fusion, and the court referred to the book ${ }^{5}$ by the cochairman, John Huizenga.

Another problem that was skilfully solved in writing the court judgement was that the first judge, who later left the case, had appointed a single court-consultant, and both parties were asked to present evidence to him so that he could decide the scientific merits of cold fusion.

It might have been expected that the choice would have been a scientist of international reputation respected by all, with a knowledge of all aspects of the problem (nuclear physics, materials science, electrochemistry and so on) and who could conduct conversations in English without an interpreter. Unfortunately, the person selected had none of these qualifications. Thus, when it was written that "the cells with electrodes of treated palladium with heavy water solutions undoubtedly produce an unexplainable quantity of heat", it does not give an opinion as to whether this was an artefact or had a scientific origin - but its scientific origin could not be fusion without nuclear products such as neutrons or tritium being recorded. Note also that evidence was submitted that the majority of such experiments did not find excess heat and the best ones rarely found any.

The future prospects of cold fusion were given as a series of escalating claims. The court judgement mentions that in July 1989 , Pons gave an interview ${ }^{6}$ where he is photographed with a cell that he claims is a boiler of which he said: "It wouldn't take care of the family's electrical needs, but it certainly could provide them with hot water year-round"; and "Simply put, in its current state it could provide boiling water for a cup of tea". Frequent claims such as these caused the court to write that Fleischmann and Pons had lost touch with reality.

The Sixth International Cold Fusion Conference is to be held from 13 to $18 \mathrm{Oc}$ tober near Sapporo in Japan. It is sponsored by the New Energy and Industrial Technology Development Organisation, which is an agency of Japan's Ministry of International Trade and Industry. Those attending will be delighted if Pons can bring his boiler and use it to make us all a cup of tea.

Douglas R. O. Morrison

CH-1296 Coppet,

Switzerland

e-mail:drom@vxcern.cern.ch

1. Del Giudice, E. \& Preparata, G. Nature 381, 729 (1996).

2. Nature 380, 369 (1996)

3. Nature 380, 367 (1996).

Nature 363, 107 (1993)

5. Huizenga, J. Cold Fusion - The Scientific Fiasco of the Century (Univ. Rochester Press, Rochester, NY, 1992).

6. Desert News, Salt Lake City, 8 July 1989.

\section{Smoke signals}

SIR - I enjoyed John Ashby's cri de coeur about the media's handling of human health issues (Nature 382, 109; 1996), especially his recommendation for a better general education in the scientific process. But before he dons his shining armour and charges Giant Ignorance, perhaps he should consider some minor issues.

(1) The scientific process is always easier to describe after the event, whereas scientists apply its principles beforehand. Even within the hallowed scientific laboratory, hypotheses become overly strengthened by the scientist's own convictions, sometimes long before the necessary experimental evidence is available. A good example is the long-held belief of many genetic toxicologists that mutagenicity $=$ carcinogenicity $=$ teratogenicity. A genetic toxicologist well known to both Ashby and me once took a significant proportion of my precious supply of thalidomide in order to follow up the possibility that this teratogen was also a mutagen, in spite of overwhelming evidence in the literature to the contrary. If we cannot learn these lessons ourselves, how can we expect to teach them to others?

(2) It is a dangerous challenge to the media when a scientific representative of a large chemical industry, with interests in the manufacture of phthalate esters, plays down the potential toxicity of these chemicals.

(3) Finally, I urge Ashby and others not to adopt a diet of three hamburgers a day. It might have a more adverse effect on their health than a normal diet accompanied by passive smoking.

\section{Oliver Flint}

Bristol-Myers Squibb,

6000 Thompson Road,

East Syracuse,

New York 13057, USA

SIR - Ashby uses the tobacco industry's campaign on passive smoking as an example of an attempt at educating the public. But this example ironically reinforces the rest of his argument on the ease of creating confusion by the misleading use of scientifically valid statistics. By focusing on the small relative risk of dying from cancer as a result of passive smoking, the tobacco industry conveniently ignores the much greater statistical likelihood, particularly in children, of illnesses such as respiratory infections, asthma and glue ear for those subjected to tobacco smoke. The industry also chooses to ignore the fact that for children, and for adults in many public or workplace environments, passive smoke exposure is not something that they can choose to avoid.

Taken away from the social context in which children cannot escape the tobacco smoke of their families, this 'choose your poison' approach between three hamburgers a day and breathing in other people's smoke is at best meaningless and, worse, offers an insidiously false reassurance, relying on the equally false public perception of eating hamburgers as a comfortable, familiar, harmless act. I hope that attempts by the tobacco industry to 'educate' us will in future fall on sceptical ears.

\section{J. Britton}

(Chairman, Tobacco Advisory Group)

Royal College of Physicians,

11 St Andrew's Place,

Regent's Park,

London NW1 4LE, UK

\section{Better late...?}

SIR - If Chadwick discovered the neutron in 1904, as again stated in your self-advertisement in the issue of 25 July 1996, why did Nature wait for close to 28 years (129, 312 ; 1932) before reporting it?

\section{Maurice Guéron}

Ecole Polytechnique,

91128 Palaiseau, France

Touché. - Editor, Nature

NATURE · VOL 382 · 15 AUGUST 1996 